\title{
Sistem Informasi Geografis Kantor Dinas di Kabupaten Tegal Berbasis Android
}

\author{
Geographic Information System Offices in Tegal District Based on Android
}

\author{
Syahrul Hakim ${ }^{1}$, Hindayati Mustafidah ${ }^{2 *}$ \\ ${ }^{1,2}$ Teknik Informatika, Fakultas Teknik dan Sains, \\ Universitas Muhammadiyah Purwokerto \\ *corr-author: h.mustafidah@ump.ac.id
}

\begin{abstract}
ABSTRAK
Pemerintah Kabupaten Tegal dalam menjalankan pemerintahannya dibantu oleh dinas daerah. Dinas Daerah merupakan unsur pelaksanaan pemerintahan di suatu daerah kota/kabupaten. Tidak tersentralisasinya serta sedikitnya informasi mengenai lokasi kantor dinas membuat masyarakat kesulitan untuk mengetahui lokasi kantor dinas maupun informasi tentang pelayanannya. Oleh karena itu dibutuhkan sebuah sistem informasi geografis untuk memberi informasi lokasi tata letak dan pelayanan kantor dinas kepada masyarakat. Penelitian ini membangun sistem informasi geografis kantor dinas di Kabupaten Tegal yang dapat diakses secara online melalui smartphone berbasis android. Informasi yang didapat meliputi data tugas/pelayanan dan lokasi kantor dinas berada. Dengan demikian masyarakat dapat terbantu untuk mencari lokasi kantor dinas dengan cepat dan mudah yang mana lokasi tersebut belum diketahui sebelumnya.
\end{abstract}

Kata kunci: kantor dinas Kabupaten Tegal, sistem informasi geografis, android, smartphone

\begin{abstract}
The Tegal Regency Government is running its government is assisted by the regional offices. The Regional Office is an element of the implementation of government in a city/regency area. Not centralized and the lack of information about the office's location makes it difficult for the public to know the location of the office and information about its services. Therefore, we need a geographic information system to provide information on the public's office layout and services area. This study built a geographic information system for the official office in Tegal Regency, accessed online via an Android-based smartphone. The information obtained includes data on assignments/services and the location of the official office. Thus, the community can help find the official office location quickly and easily where the site has not been previously known.
\end{abstract}

Keywords: Tegal regency office, geographic information system, android, smartphone

\section{PENDAHULUAN}

Kabupaten Tegal adalah salah satu kabupaten di Provinsi Jawa Tengah. Ibukotanya adalah Slawi, sekitar $14 \mathrm{~km}$ sebelah selatan Kota Tegal. Kabupaten ini berbatasan dengan Kota Tegal dan Laut Jawa di utara, Kabupaten Pemalang di timur, Kabupaten Banyumas di selatan, serta Kabupaten Brebes di selatan dan barat. Kabupaten Tegal terdiri atas 18 
kecamatan, yang dibagi lagi atas sejumlah desa dan kelurahan. Pusat pemerintahan berada di Kecamatan Slawi. Dulunya merupakan kota kecamatan, yang kemudian dikembangkan menjadi ibukota kabupaten yang sebelumnya berada di Kota Tegal.

Pemerintah Kabupaten Tegal dalam website tegalkab.go.id memberikan informasi mengenai dinas di Kabupaten Tegal namun informasi itu hanya terkait alamat dan kontak instansi saja (Dinkominfo Kabupaten Tegal, 2017). Dengan perkembangan pembangunan yang pesat tentu hal itu masih kurang dalam memberikan informasi karena tidak semua masyarakat mengetahui alamat itu. Sehingga dibutuhkan sebuah informasi pemetaan lokasi tata letak kantor dinas itu berada. Dengan demikian informasi yang diperoleh bukan hanya textual saja tetapi dalam bentuk spasial atau peta yang interaktif yang akan memudahkan masyarakat untuk melakukan pencarian lokasi kantor dinas.

Kantor dinas pemerintah Kabupaten Tegal meliputi 18 (delapan belas) jenis dinas yang membantu pelaksanaan urusan pemerintah daerah yaitu (Peraturan Bupati Kabupaten Tegal, 2016):

1. Dinas Pendidikan dan Kebudayaan

2. Dinas Kesehatan

3. Dinas Pekerjaan Umum

4. Dinas Perumahan Rakyat, Kawasan Permukiman, Tata Ruang dan Pertanahan

5. Dinas Sosial

6. Dinas Perindustrian dan Tenaga Kerja

7. Dinas Pemberdayaan Perempuan, Perlindungan Anak, Pengendalian

Penduduk dan Keluarga Berencana

8. Dinas Lingkungan Hidup

9. Dinas Kependudukan dan Pencatatan Sipil

10. Dinas Pemberdayaan Masyarakat dan Desa

11. Dinas Perhubungan

12. Dinas Komunikasi dan Informatika

13. Dinas Penanaman Modal dan Pelayanan Terpadu Satu Pintu

14. Dinas Pariwisata, Pemuda dan Olah Raga

15. Dinas Kearsipan dan Perpustakaan

16. Dinas Pertanian dan Ketahanan Pangan

17. Dinas Kelautan, Perikanan dan Peternakan;

18. Dinas Perdagangan, Koperasi, Usaha Kecil dan Menengah

Sistem Informasi Geografis (SIG) adalah sebuah sistem yang didesain untuk menangkap, menyimpan, memanipulasi, menganalisa, mengatur seluruh jenis data geografis. Sistem ini dirancang untuk mengumpulkan, menyimpan dan menganalisis objekobjek dan fenomena dimana lokasi geografis merupakan karasteristik yang penting atau kritis untuk dianalisis (Irwansyah, 2013). Sistem informasi geografis dapat diuraikan menjadi beberapa subsistem yang dapat dilihat pada Gambar 1 . 


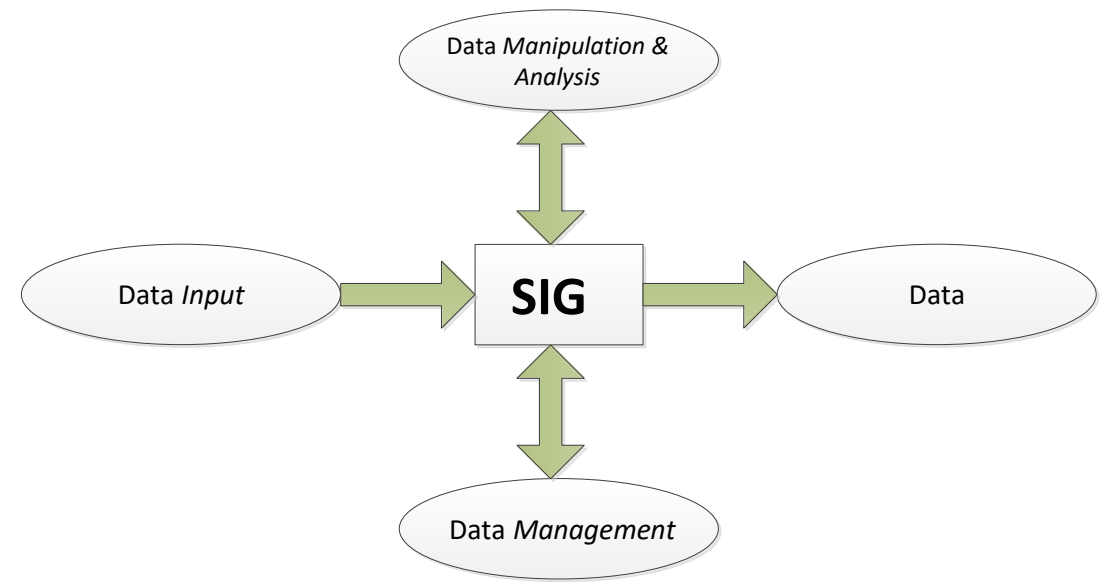

Gambar 1. Subsistem SIG (Irwansyah, 2013)

Sistem Informasi Geografis (SIG) juga dapat diterapkan untuk memberikan informasi tata letak lokasi kantor dinas di Kabupaten Tegal dalam bentuk peta digital. Sistem ini merelasikan data spasial (lokasi geografis) dengan data non spasial, sehingga para pengguna dapat membuat peta dan menganalisa informasinya dengan berbagai cara. Sistem informasi geografis ini akan dikembangkan dengan mobile android.

Android merupakan salah satu platform dari perangkat Smartphone. Salah satu keutamaan dari Android yaitu lisensinya bersifat terbuka (open source) dan gratis (free) sehingga bebas untuk dikembangkan karena tidak ada biaya royalti maupun didistribusikan dalam bentuk apapun. Hal ini memudahkan para programmer untuk membuat aplikasi baru di dalamnya. Selain itu Android juga media yang dapat mengakses kemampuan SIG lewat Google Map. Android merupakan generasi baru platform mobile, platform yang memberikan pengembang untuk melakukan pengembangan sesuai yang diharapkannya. Android didistribusikan di bawah Lisensi Apache Software (ASL/Apache 2), yang memungkinkan untuk distribusi kedua dan seterusnya. Pengembang aplikasi android diperbolehkan untuk mendistribusikan aplikasi di bawah skema lisensi apapun yang di inginkan (Nazruddin, 2010), seperti yang dikembangkan oleh (Piarsa et al., 2015) dalam pengembangan SIG mobile.

Penelitian yang berkaitan dengan penelitian ini adalah penelitian tentang sistem informasi geografis kantor dinas bangkalan dengan tujuan untuk membangun suatu system yang mempermudah dalam proses pencarian lokasi dan informasi layanan di tiap kantor dinas wilayah Madura khususnya bangkalan. System yang telah dibangun adalah pemetaan infrastruktur kantor dinas kota bangkalan dengan system layanan berbasis lokasi (LBS) berbasis android (Anamisa and Rachmad, 2015). Selain itu, Novita et al. (2015) juga telah mengembangkan SIG untuk mengidentifikasi lokasi pemukiman di Palembang, sementara Arianto and Udjulawa (2015) mengembangkan SIG untuk pemetaan kantor dinas provinsi Palembang.

Berdasarkan uraian yang telah disampaikan, belum adanya sistem informasi geografis kantor dinas di Kabupaten Tegal yang dapat diakses masyarakat secara online menyebabkan terhambatnya informasi pelayanan bagi masyarakat. Oleh karena itu, dibangun sebuah sistem informasi geografis kantor dinas di Kabupaten Tegal dengan visualisasi yang diterapkan pada android meliputi informasi rute jalan, pelayanan kantor dan waktu perjalanan. Dengan adanya sistem ini diharapkan dapat membantu masyarakat dalam menemukan informasi pelayanan kantor dinas yang berada di Kabupaten Tegal dengan mudah, cepat dan efisien. 


\section{METODE}

Data penelitian dikumpulkan dari sumber dokumen tentang Kantor Dinas di Kabupaten Tegal pada Sekretaris Daerah Bidang Organisasi Kabupaten Tegal dan data dari Google Maps. Data dari Google Maps berfungsi untuk mendapatkan lokasi longitude dan latitude dari masing-masing Kantor Dinas di Kabupaten Tegal.

Model pengembangan yang digunakan dalam sistem ini adalah air terjun (waterfall) seperti pada Gambar 2.

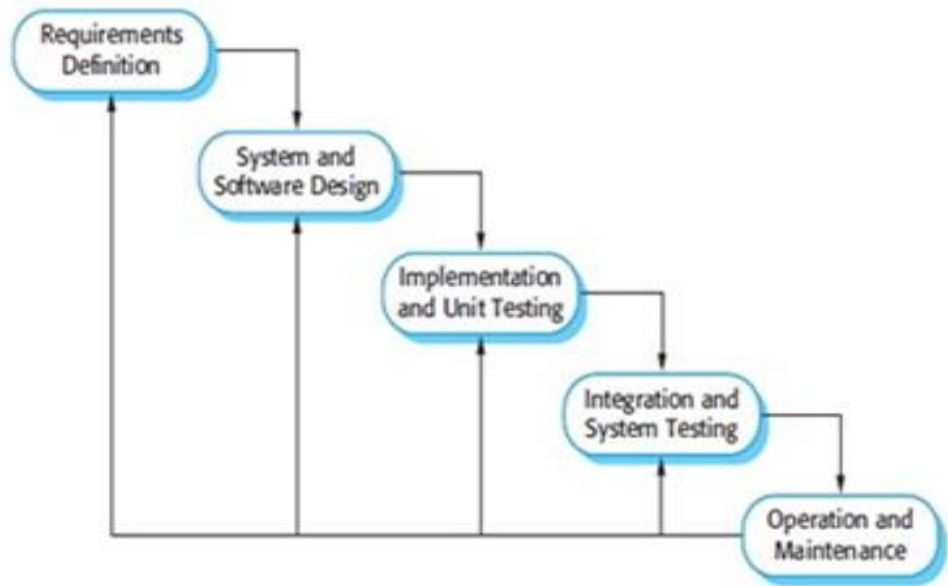

Gambar 2. Waterfall Model (Sommerville, 2011)

Tahap requirement analysis and definition yang merupakan tahapan tahapan pertama, dilakukan pengumpulan dan analisis kebutuhan meliputi kebutuhan data maupun kebutuhan fungsional untuk mengembangkan system yang berupa kebutuhan software dan hardware. Tahap selanjutnya adalah system and software design yaitu menerjemahkan dari kebutuhan perangkat lunak menjadi bentuk rancangan dengan tujuan agar dapat diimplementasikan menjadi program. Tahap implementation and unit testing dilakukan penyusunan kode program untuk kemudian diuji per unit program supaya terbebas dari kesalahan. Tahapan selanjutnya integration and system testing dilakukan penyatuan dari unit-unit program menjadi satu kesatuan system dan dilakukan pengujian terhadap system secara menyeluruh. Tahapan terakhir yaitu operation and maintenance, merupakan saat program yang dihasilkan akan dioperasikan dan dilakukan pemeliharaan.

Rancangan system dibangun menggunakan Use Case Diagram sebagaimana pada Gambar 3. Sementara itu, rancangan tabel data kantor dinas yang diberi nama tabel datakantor, disajikan pada Tabel 1. 


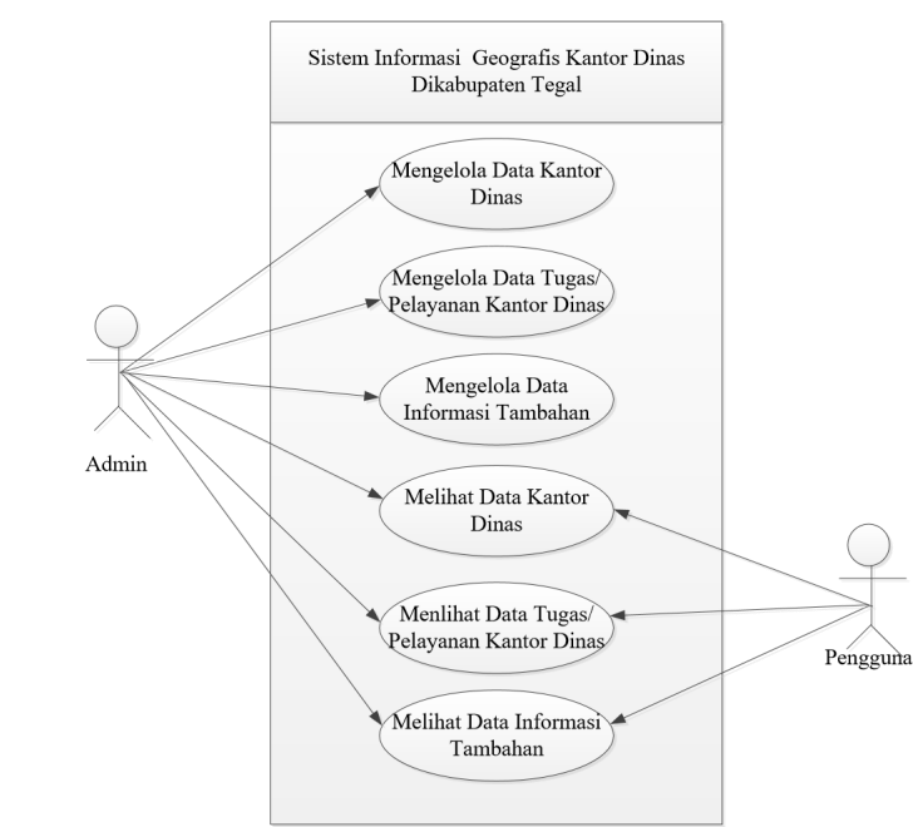

Gambar 3. Use Case Diagram Sistem Informasi Geografis Kantor Dinas di Kabupaten Tegal

Tabel 1. Rancangan tabel data kantor dinas

\begin{tabular}{|c|c|c|}
\hline Nama Kolom & Tipe Data & Keterangan \\
\hline Kantor_id & varchar & $\begin{array}{l}\text { Merupakan kolom kode kantor pada tabel } \\
\text { kantor dinas. }\end{array}$ \\
\hline Kantor_nama & varchar & $\begin{array}{l}\text { Merupakan kolom untuk mengisi nama } \\
\text { kantor dinas. }\end{array}$ \\
\hline Kepala_kantor & varchar & $\begin{array}{l}\text { Merupakan kolom untuk mengisi kepala } \\
\text { kantor dinas. }\end{array}$ \\
\hline Kantor_alamat & varchar & $\begin{array}{l}\text { Merupakan kolom untuk mengisi alamat } \\
\text { kantor dinas. }\end{array}$ \\
\hline Kantor_tugas & varchar & $\begin{array}{l}\text { Merupakan kolom untuk mengisi } \\
\text { tugas/pelayanan kantor dinas. }\end{array}$ \\
\hline Kantor_notel & varchar & $\begin{array}{l}\text { Merupakan kolom untuk mengisi nomer } \\
\text { telephone kantor dinas. }\end{array}$ \\
\hline Kantor_email & varchar & $\begin{array}{l}\text { Merupakan kolom untuk mengisi email } \\
\text { kantor dinas. }\end{array}$ \\
\hline latitude & float & $\begin{array}{l}\text { Merupakan kolom untuk mengisi lokasi } \\
\text { latitude kantor dinas. }\end{array}$ \\
\hline longitude & float & $\begin{array}{l}\text { Merupakan kolom untuk mengisi lokasi } \\
\text { longitude kantor dinas. }\end{array}$ \\
\hline gambar & varchar & $\begin{array}{l}\text { Merupakan kolom untuk mengisi gambar } \\
\text { kantor dinas. }\end{array}$ \\
\hline
\end{tabular}




\section{HASIL DAN PEMBAHASAN}

\section{SplashScreen}

Splash screen merupakan tampilan pertama ketika kita menjalankan aplikasi, berisi logo aplikasi. Tampilanya seperti pada Gambar 4 berikut.

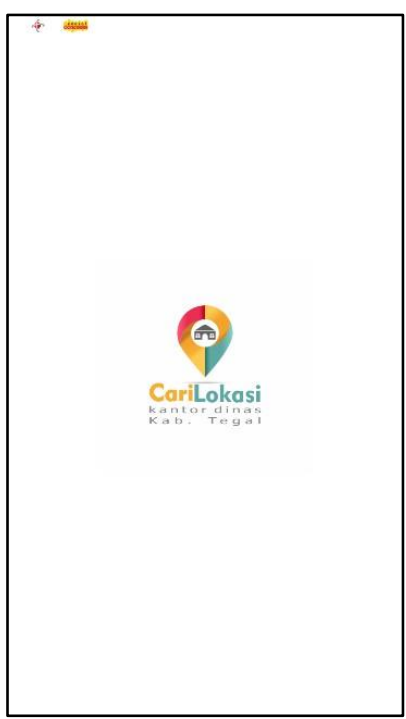

\section{Gambar 4. Tampilan Splash Screen}

\section{Halaman utama}

Halaman utama aplikasi berisi tentang nama aplikasi dan logo aplikasi. Halaman ini berisi menu bantuan, menu tentang aplikasi, menu drawer. Tampilan halaman utama aplikasi dapat dilihat seperti pada Gambar 5 berikut.

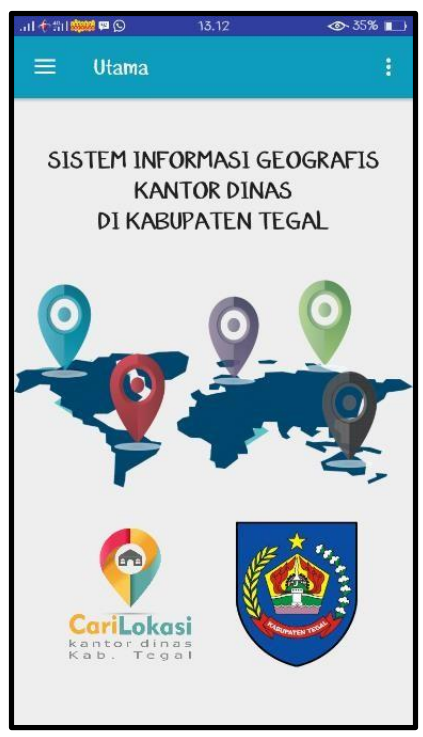

Gambar 5. Tampilan halaman utama 


\section{Drawer menu aplikasi}

Halaman ini berfungsi sebagai tempat menu-menu aplikasi. Menu ini terdiri dari menu peta kantor, daftar kantor dinas, pelayanan kantor dinas, dan tentang, tampilan main drawer menu aplikasi dapat dilihat seperti pada Gambar 6.

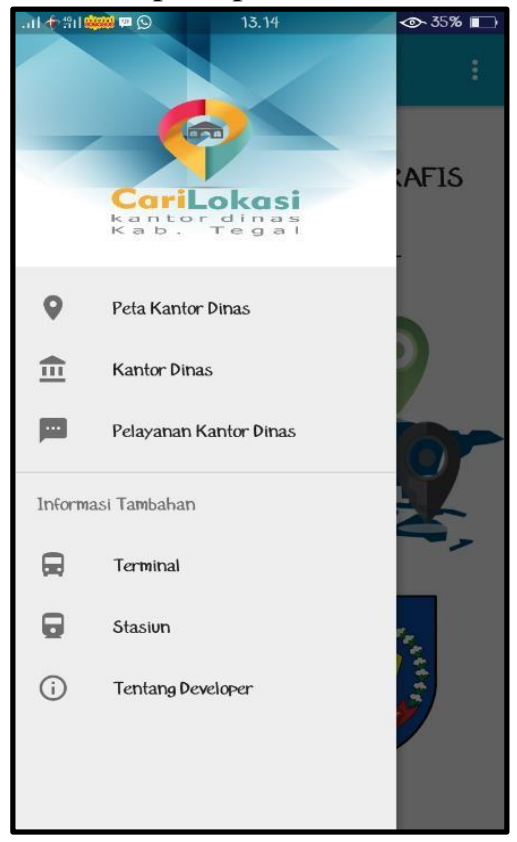

\section{Gambar 6. Tampilan drawer menu aplikasi}

\section{Tampilan list data}

Halaman ini menampilkan daftar data kantor dinas di Kabupaten Tegal. Adapun tampilannya seperti pada Gambar 7 berikut.

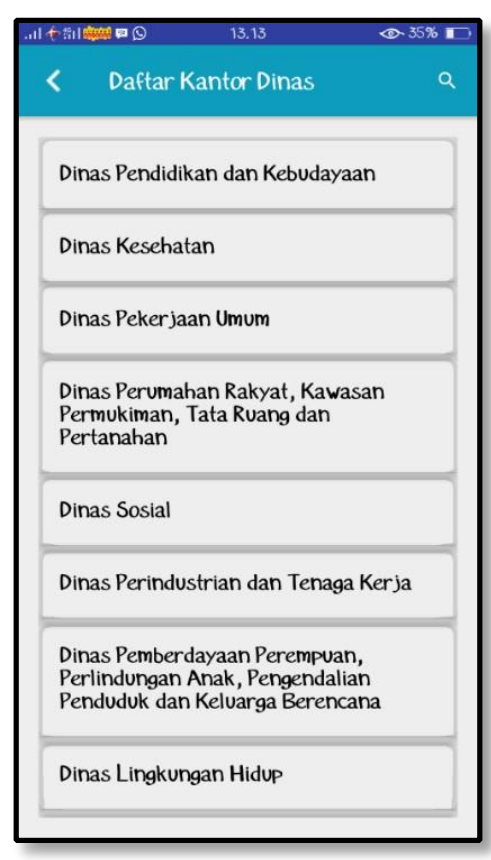

Gambar 7. Tampilan list data 


\section{Detail Dinas}

Pada daftar nama dinas jika diklik maka akan masuk halaman detail sesuai dengan nama dinas yang diklik. Tampilan detail dinas dilihat pada Gambar 8 .

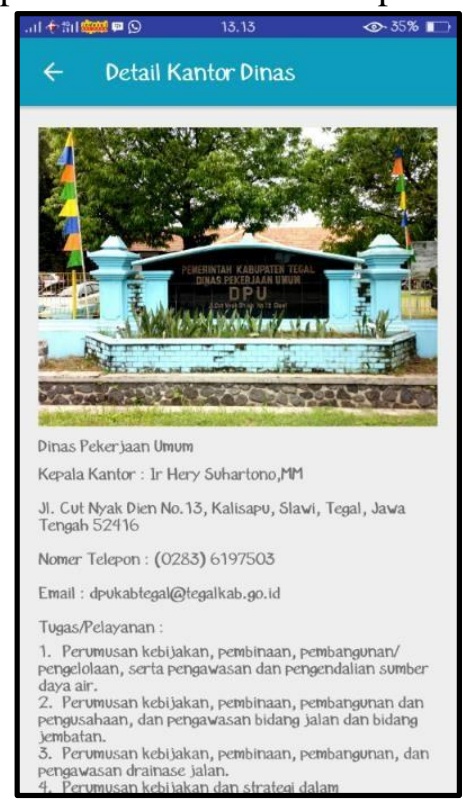

Gambar 8. Tampilan detail data

\section{Peta kantor dinas}

Halaman peta kantor dinas berisi sebagai pemandu seluruh tempat kantor dinas yang berada di Kabupaten Tegal. Pada halaman ini terdapat fitur untuk mengetahui lokasi pengguna dan untuk navigasi, sebagaimana pada Gambar 9.

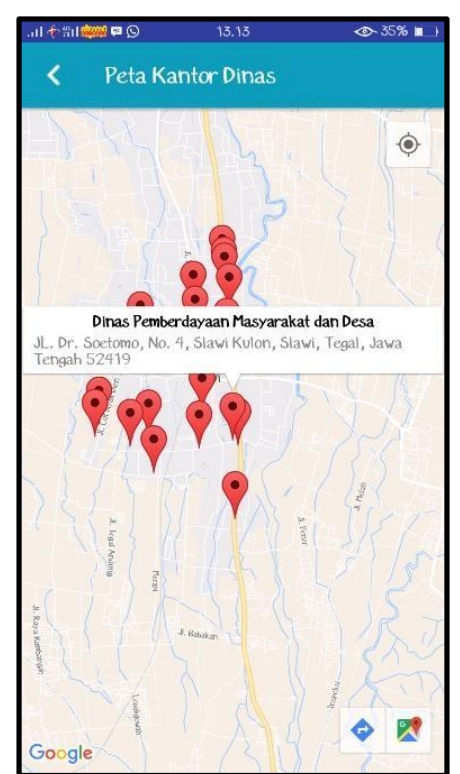

Gambar 9. Tampilan peta kantor dinas 


\section{Halaman Direction}

Pada halaman ini berfungsi menampilkan penunjuk rute dari posisi user berada sampai lokasi Kantor Dinas tujuan. Tampilan direction dapat dilihat pada Gambar 10 berikut.

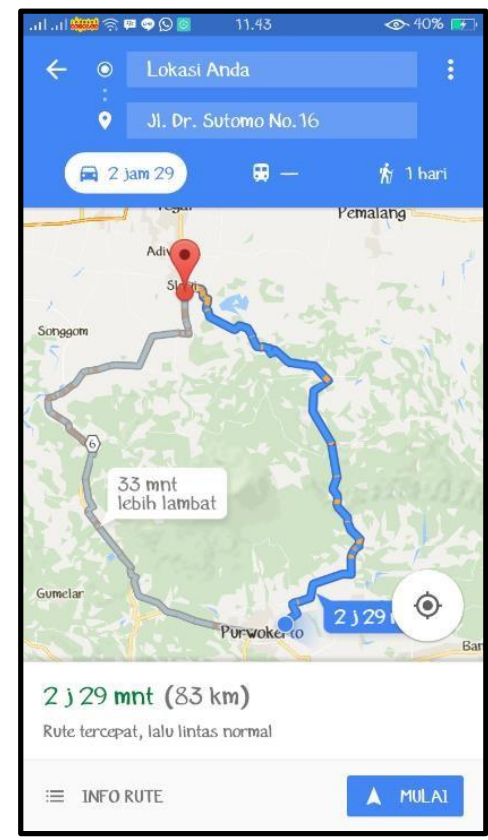

\section{Gambar 10. Tampilan Peta Direction}

\section{Halaman home admin}

Halaman yang pertama kali dilihat ketika admin berhasil login adalah halaman home, tampilannya seperti pada Gambar 11 berikut.

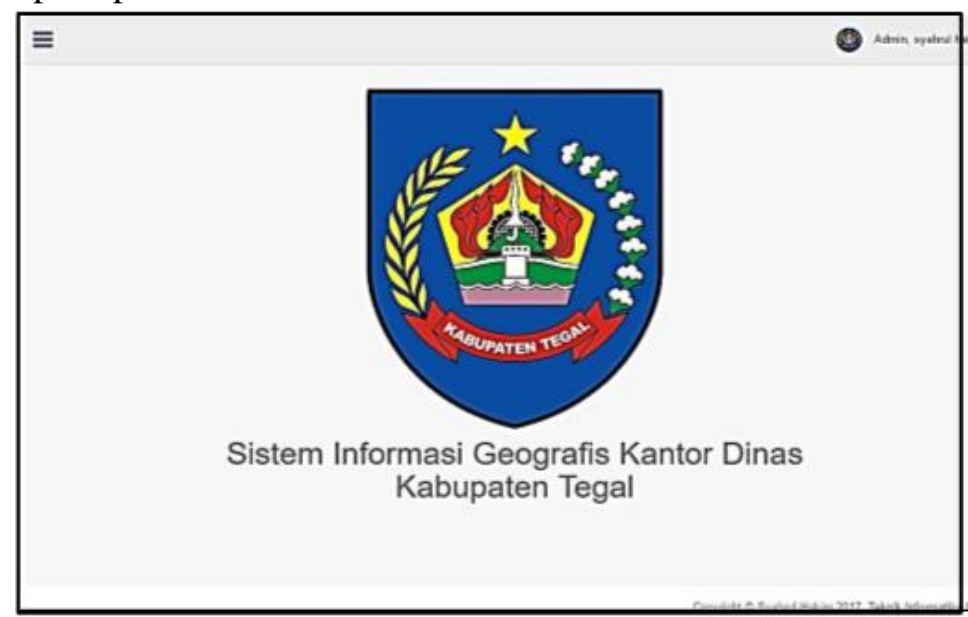

Gambar 11. Tampilan halaman home

\section{Halaman pengolahan data Dinas}

Halaman ini berisi list/daftar data yang telah dimasukkan oleh admin. Dalam bagian action admin bisa memilih untuk melihat \& menambah data, mengubah, dan menghapus data, tampilannya seperti pada Gambar 12 berikut. 


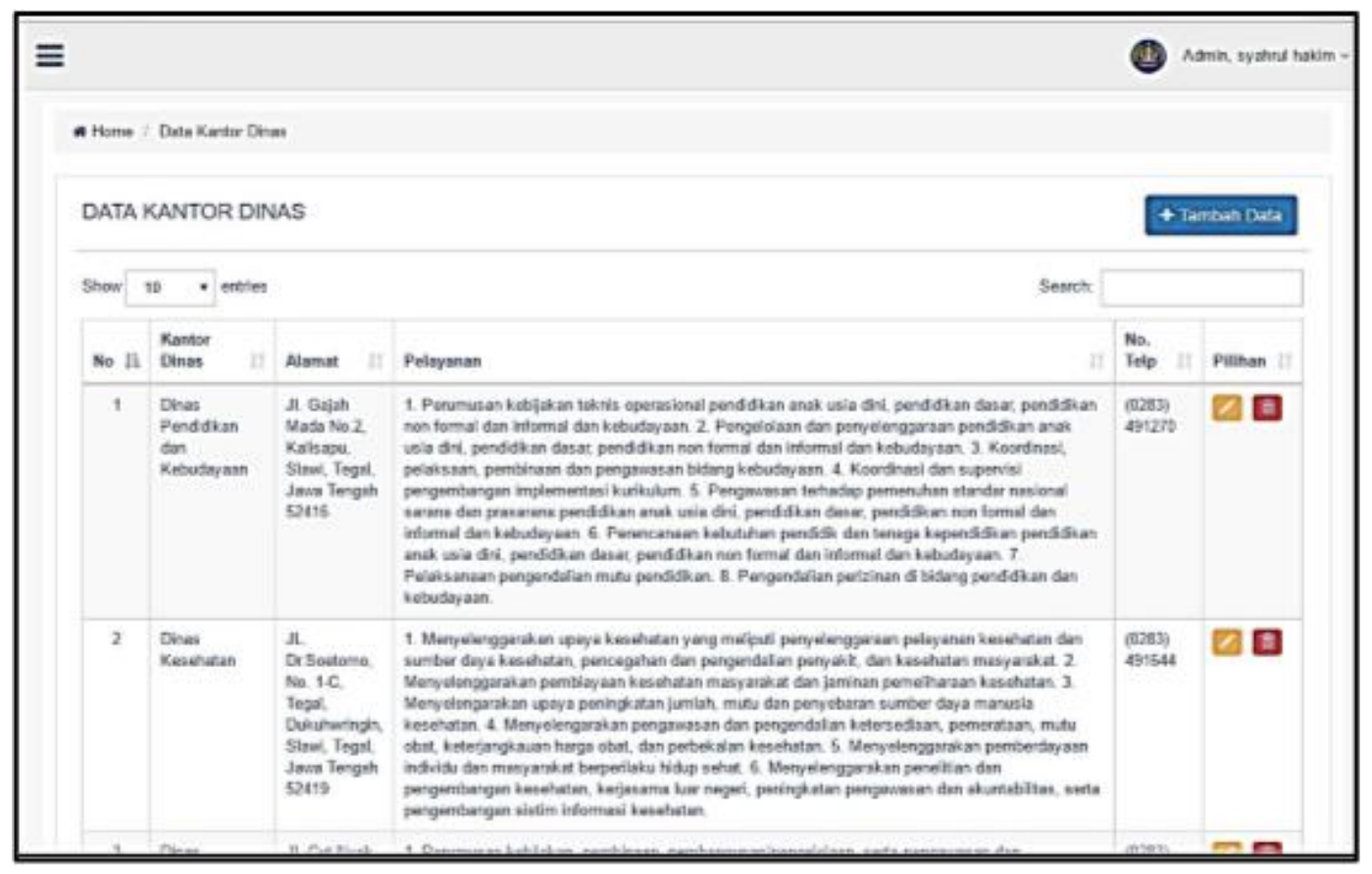

\section{Gambar 12. Halaman list data}

Berdasarkan hasil aplikasi yang telah dipaparkan, dilakukan pengujian terhadap aplikasi menggunakan metode blackbox testing. Hasil pengujian menunjukkan bahwa aplikasi berupa system informasi geografis ini memenuhi unsur-unsur sebagai sistem dan sesuai dengan harapan yaitu dapat digunakan sebagai media informasi bagi masyarakat yang membutuhkan sarana informasi terhadap lokasi dan layanan kantor dinas di Kabupaten Tegal.

\section{KESIMPULAN}

Pengembangan aplikasi sistem informasi geografis Kantor Dinas di Kabupaten Tegal berbasis android ini memberikan kemudahan kepada masyarakat, khususnya masyarakat Kabupaten Tegal dalam pencarian lokasi Kantor Dinas di Kabupaten Tegal. Selain informasi lokasi Kantor Dinas, masyarakat juga dapat mengetahui fasilitas tugas/pelayanan dari masing-masing Kantor Dinas melalui smartphone yang dalam penggunaannya mudah dan efesien. Aplikasi sistem infomasi geografis ini dapat dikembangkan lagi dengan mempertimbangkan hal-hal berikut sebagai masukan dalam pengembangan selanjutnya yaitu: 1) menggunakan login dan sign-up aplikasi, agar admin bisa mengetahui informasi tentang pengguna aplikasi android dan adanya kilas balik dari pengguna/user; 2) setelah ditambahkan fitur login dan sign-up aplikasi, selanjutnya bisa ditambahkan fitur rating tetang pelayanan yang diberikan oleh Kantor Dinas agar bisa dijadikan evaluasi kerja dan meningkatkan pelayanan untuk masyarakat.

\section{DAFTAR PUSTAKA}

Anamisa, D.R. and Rachmad, A., 2015. Aplikasi Pemetaan Kantor Dinas Di Kabupaten Bangkalan-Madura Berbasis Android. JSiI (Jurnal Sistem Informasi), 2(4), pp.2428.

Arianto, R.D. and Udjulawa, D., 2015. SISTEM INFORMASI GEOGRAFIS KANTOR DINAS PROVINSI SUMATERA SELATAN BERBASIS ANDROID. , pp.1-12. 
Dinkominfo Kabupaten Tegal, 2017. Halaman Kontak Pemerintah Kabupaten Tegal. http://tegalkab.go.id/kontak.php. Available at: http://tegalkab.go.id/kontak.php [Accessed March 14, 2017].

Irwansyah, E., 2013. SISTEM INFORMASI GEOGRAFIS: Prinsip Dasar dan Pengembangan Aplikasi, Yogyakarta: Digibooks.

Nazruddin, 2010. Android Pemrograman Aplikasi Mobile Smartphone dan Tablet PC Berbasis Android, Bandung: Informatika.

Novita, L., Abdillah, L.A. and Muzakir, A., 2015. Geographic Information Systems of Android-Based Residential Locations in Palembang. In The 4th ICIBA 2015, International Conference on Information Technology and Engineering Application. pp. 236-241.

Peraturan Bupati Kabupaten Tegal, 2016. Kedudukan, Susunan Organisasi, Tugas dan Fungsi Serta Tata Kerja Dinas - Dinas Daerah dan Satuan Polisi Pamong Praja Kabupaten Tegal.

Piarsa, I.N., Hadi, E.S. and Wirdiani, N.K.A., 2015. Rural Road Mapping Geographic Information System Using Mobile Android. International Journal of Computer Science Issues (IJCSI), 12(3), p.95.

Sommerville, I., 2011. Software Engineering, 9ed., Boston: Pearson Education Inc. 